\title{
The relevance of anatomy and morbid anatomy for medical practice and hence for postgraduate and continuing medical education of doctors
}

\author{
*A.H. Crisp \\ St George's Hospital Medical School, Cranmer Terrace, London SW17 ORE, UK.
}

\begin{abstract}
Summary: A case is presented for the durability of anatomy including dissection of the cadaver and of morbid anatomy as elements in medical education and practice. It is these subjects, as consistently relevant over the centuries for medical practice as are communication skills, that are our hallmark as doctors. It is submitted that we should take stock very carefully of their relevance to us before it is too late easily to redress the balance, given the major trends of the last two decades.
\end{abstract}

These days molecular biology needs no special advocacy as a subject in medical education. It is anatomy that is under seige. The word 'doctor' means 'teacher' - someone who has knowledge and understanding to transmit. It may have become immutably attached to medical practitioners during the Renaissance when, despite fierce resistance from the church, man first began systematically to dissect the cadaver in his relentless exploration of the mysteries of the body. Even today, there are those ${ }^{1}$ who argue that such dissection, as the basis of modern scientific method, holds the key to man's dehumanization! Anatomy, in its broadest sense, certainly was at the mainspring of Western man's new curiosity, and does require him to reframe the basis of reverence for life. But has it now become a spent force? As I have said, biochemistry, immunology, etc., and their clinical cousins, need little defence - they currently comprise the scientific empires in medical science. It is normal anatomy and morbid anatomy that we need to consider at a time when these are significantly diminishing within the curriculum, displaced by other subjects.

The new Recommendations on the Training of Specialists $(1987)^{2}$ produced by the Education Committee of the General Medical Council (GMC) address, not the details of specialist training itself (except to transmit what the Royal Colleges, Faculties and Joint Committees require), but the general necessary

Correspondence: Professor A.H. Crisp, M.D., D.Sc, F.R.C.P., F.R.C.P.(E), F.R.C.Psych.

Accepted: 24 November 1988

*Professor Crisp was Chairman of the Education Committee of the General Medical Council 1982-1988 competences of the practitioner whatever his or her specialty.

Figure 1 illustrates the way in which such medical education develops. Anatomy is first learned as part of medical science and in the process contributes to self-directed learning and problem-solving skills. It feeds into clinical skills whatever the specialty and, I shall argue, into conduct.

It is the responsibility of our undergraduate teachers to educate doctors to begin to practise to high standards. It is to this end that the medical register exists. The 1987 GMC Recommendations concerning subsequent postgraduate training identify a round dozen of attributes of which just the one relates to specific special competences. If that specialism is say, surgery, or obstetrics and gynaecology, then a knowledge of regional anatomy and morbid anatomy assumes a central significance in such specialist training. Psychiatrists need an expert knowledge of the apparatus of the mind and then find that that apparatus is not only the brain but the body in its entirety. Radiologists and physicians today invade the body dramatically with their new techniques and clearly have always needed broad expert knowledge of structure as well as function, and so on.

Indeed, the hallmark of the registered medical practitioner is his licence to invade the body in the interests of his patient. This invasion can be investigative and diagnostic in its intent, primarily the clinical examination of the patient and his or her body including its accessible cavities. It can also be therapeutic in its intent. This may be chemical, with knives or needles, radiological or with feelings and ideas (sometimes perceived as the most invasive of all, 
Applicable knowledge

Scientific method

Self directed learning

Problem solving skills

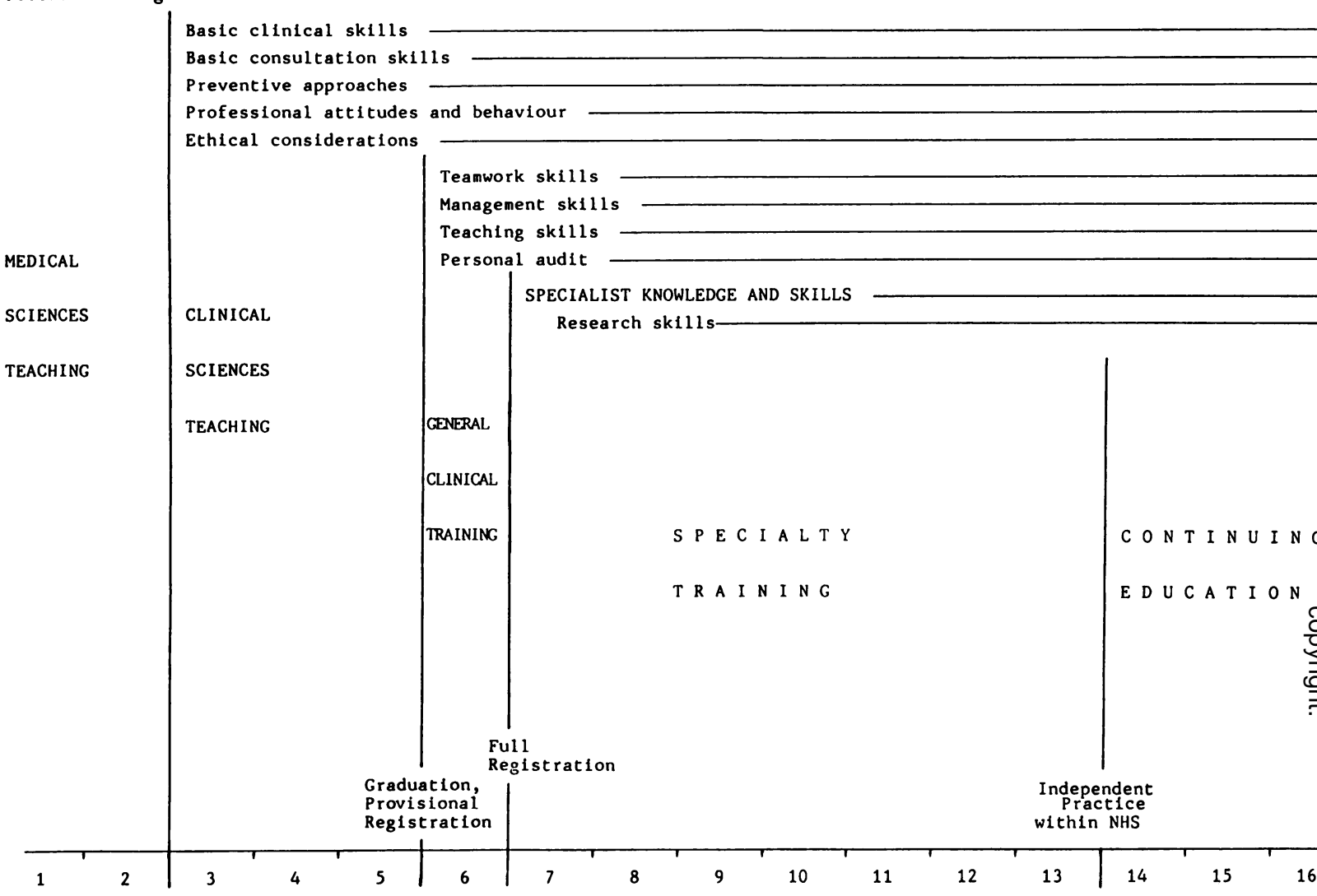

Y E A R S

Figure 1 Continuing development of medical education.

not always reversible and not the prerogative of the medical practitioner but powerful in his or her hands). How does this licence come about?

The medical curriculum, especially at undergraduate level and most especially at the level of basic medical science teaching, where it can be in the hands of non-medical (non-clinical) personnel, is a nonelective course unit degree or intermediate degree potentially of a remarkably fragmented kind. It is a major task to integrate it and the body must be the integrative focus. The undergraduate medical student studies very little in depth, which is not surprising given that the basic medical science course contains at least nine potentially separate subjects. The student may, with enlightenment, study some aspect in depth, especially if pursuing an intercalated degree, but only a minority can do this. The medical student is less knowledgeable and skilled in biochemistry than those studying for a biochemistry degree, less knowledgeable in physiology or pharmacology or immunology or medical statistics or medical psychology or medical sociology or medical genetics than other non-medical students pursuing these subjects individually in their separate science faculty courses. He is a jack of all trades. The one subject the medical student studies and practices that no one else studies in the same way is anatomy involving dissection of the cadaver. It is from this that his clinical competence and confidence derives.

I suggest that dissection of the human body is an initiation into the role of the doctor. After undertaking it the person is different. He may and should feel different and he is viewed differently. Is this a good thing? Potentially, of course, it may blunt his sen- 
sitivity. He or she may have to learn again the capacity for empathy but this time consciously so and from a new position. It is this twofold development and strength that will enable the doctor thereafter to confront, daily if necessary, intractable pain, imminent death, serious disease, etc., from which most others turn away, and hopefully with detached concern and skill.

It would seem then that this study of anatomy is one distinguishing feature that may entitle the medical student, as distinct from other students of health care, after the first two or so years, to go on to those clinical studies as an undergraduate with which we are all familiar. It is his graduation from these that provides him with the right to practise and, in that graduation process, we usually emphasize the importance, and indeed the primacy, of clinical skills. For instance, the student's capacity to properly and sensitively conduct an interview, a pelvic examination, a rectal examination, an examination of the breast, of the male genitalia, of the axilla and so on.

By this time members of the public, such are the standards they expect us to have achieved, will often willingly and unselfconsciously and usually without ulterior motive make their bodies freely available for examination - for the doctor's inspection, palpation, probing, in a way which they may never or very rarely otherwise do. It is his knowledge of anatomy and familiarity with the body and with handling it and the patient's perception that this is so that gives him this authority over and above any that derives from his knowledge of body chemistry. His active dissection of the body will have contributed to those practical skills (he has to be a doer) which he may now require if he is to remain registered, whatever his chosen specialty. These practical skills might properly include, for instance, those necessary for cardiopulmonary resuscitation, reducing a dislocated shoulder, doing an emergency tracheostomy, assisting in a delivery, stemming a post partum haemorrhage, managing a grand mal seizure - whatever may be required of him in the way of dealing with such relatively common emergencies, all of which involve gross living anatomy.

A study of function can assist us in learning our anatomy but equally a knowledge of anatomy can betray its function and so it can lead us to secure an understanding of that. The piston ring of a cylinder in a car engine subserves a function which it was designed to do but it is easy enough to guess its function when you study its structure.

There would seem to me to be many factors coming together now to produce an overswing of the pendulum in this area. Anatomy recently commanded

\section{References}

1. Lewis, C.S. The Abolition of Man. Oxford University Press, Oxford, 1943. huge tracts of the curriculum. Many unnecessary details were taught. Powerful teachers in anatomy and pathology in the past held sway. Now they have been displaced and, sometimes, barely exist. Recruitment to pathology and even to surgery, both subjects in a direct line of development from anatomy, is less robust than it used to be. Perhaps the changing nature of medical education is attracting or even leading to the selection of a different kind of recruit. Is this what the public needs? Surely it is the doctor's familiarity with the living body and his right to invade it that has been his unique characteristic; other aspects of his practice he shares with others.

There is now some concern about this matter. We should note that, in some medical schools around the world with innovative curricula, an attempt has been made to do away with dissection in anatomy but they have now backtracked because of the unease and lack of confidence in dealing with the gross anatomy of the body that their graduates have expressed. There are new approaches today in the teaching of anatomy which may help us to redress the balance or hold the line in the United Kingdom to some extent if we wish it.

If anatomy, including dissection of the normal body, is a centrally important subject in medical education, then the same obviously applies to morbid anatomy. The autopsy can surely be an important opportunity to learn, not least when it is a matter for personal audit and peer review. It is at autopsy that we see our failures and mistakes.

I have been arguing the case for normal and morbid anatomy including dissection as providing an immutable cornerstone of medical education and as capable of producing a durable impact on the developing doctor. In the postgraduate sphere there are clearly some specialties that return particularly to the subjects of anatomy, normal and morbid. Surgery is the prime example. Perhaps, in other specialties, postgraduate training including continuing medical education, should, in this respect, remember to turn to "living anatomy' for reinforcement of knowledge and skills. For instance, the Education Committee's Recommendations on the Training of Specialists specifically require us all to be competent in cardio pulmonary resuscitation where knowledge of living structure is of the essence. Our expertise in, and relationship with, the other laboratory sciences will change as technology changes and our relationship with non-medical science changes. Morbid anatomy and the autopsy are more likely to be durable elements in medical practice and as necessary and informative to us as ever.

2. Education Committee, General Medical Council. Recommendations on the Training of Specialists. October, 1987. 